\title{
Increase in Cardiac Troponin I in a Lamb with Tetralogy of Fallot
}

\author{
Elisa Barp NEUWALD ${ }^{1) *}$, Frederico Aécio Carvalho SOARES ${ }^{2}$, Cristina Terres DREYER ${ }^{3)}$, Samuel CARNESELLA ${ }^{3)}$, \\ Angelica Terezinha Barth WOUTERS ${ }^{4}$, Félix Hilario Diaz GONZÁLEZ1) and David DRIEMEIER ${ }^{4)}$ \\ 1) Department of Veterinary Clinical Pathology, Federal University of Rio Grande do Sul, Porto Alegre, RS, Brazil \\ 2) Veterinary Clinical Hospital, Federal University of Rio Grande do Sul, Porto Alegre, RS, Brazil \\ ${ }^{3)}$ Department of Small Ruminants Medicine, Federal University of Rio Grande do Sul, RS, Brazil \\ 4) Department of Veterinary Pathology, Federal University of Rio Grande do Sul, Porto Alegre, RS, Brazil
}

(Received 21 January 2013/Accepted 6 May 2013/Published online in J-STAGE 20 May 2013)

ABSTRACT. This study describes a case of tetralogy of Fallot in a lamb showing failure to thrive and signs of respiratory distress. Physical examination, electrocardiography, thoracic radiographies, echocardiography and cardiac troponin I evaluation were performed. The value of cardiac troponin I was compared with the values of 10 healthy lambs of the same age and breed, and the affected animal demonstrated an increase in cardiac troponin I. Due to the poor prognosis, euthanasia was indicated, and necropsy confirmed the diagnosis. This is the first report of an increase in cardiac troponin I in a lamb with tetralogy of Fallot.

KEY WORDS: cardiac anomaly, congenital heart disease, goat.

doi: 10.1292/jvms.13-0034; J. Vet. Med. Sci. 75(10): 1371-1373, 2013

Congenital cardiac defects are uncommon in ovines, and in a large series of necropsied lambs, they occurred in only $1 \%$ of the animals [3]. Tetralogy of Fallot is a rare congenital heart disease that has previously been reported in sheep [7] and several species of domestic animals $[1,4,9,12]$. The disease is characterized by four defects: pulmonary valve stenosis, ventricular septal defect, aortic dextroposition and right ventricular hypertrophy [13]. Biomarkers of cardiac injury are widely used in human medicine, and their importance in veterinary medicine has become evident in recent years. Cardiac troponins are present at high concentrations in cardiac myocytes, and their release into the blood stream occurs in cardiac lesions [2]. The aim of this study is to report the elevation of serum cardiac troponin I in a lamb with tetralogy of Fallot.

A three-month-old male Corriedale lamb was referred to the Veterinary Hospital of Federal University of Rio Grande do Sul, Brazil, with a history of failure to thrive, respiratory distress and exercise intolerance. On physical examination, cyanosis of the mucous membranes and abdominal distention compatible with ascites were found. Similar clinical findings were detected in another study [7] with the animal showing respiratory distress and cyanosis, however, the lamb in the present study showed also failure to thrive. Cyanosis occurs in patients with tetralogy of Fallot due to the right to left shunt, because of the pulmonary stenosis and biventricular origin of the aorta [7]. On thoracic auscultation, a cardiac murmur was detected in all areas of cardiac auscultation. A grade 3 out of 6 holosystolic murmur was heard at mitral, tri-

*Correspondence to: Neuwald, E. B., Department of Veterinary Clinical Pathology, Federal University of Rio Grande do Sul, 9090 Bento Gonçalves avenue, Porto Alegre, RS 91540-000, Brazil. e-mail: eneuwald@ibest.com.br

(C)2013 The Japanese Society of Veterinary Science cuspid and aortic valve areas. A grade 4 out of 6 holosystolic murmur was heard at the pulmonary valve area.

The patient was submitted to thoracic radiography, electrocardiography and echocardiography, and blood samples were collected for the measurement of cardiac serum troponin I. Thoracic radiography showed an overall increase in the cardiac silhouette, and animals with tetralogy of Fallot may have right atrium and ventricle enlargement [11]. The electrocardiographic patterns in animals evaluated in that clinical case were similar to those reported in a study on healthy young sheep of the same breed [10], except for heart rate (HR). In the present case, the animal had tachycardia with the HR ranging between 160 and 170 beats per min, which was most likely associated with congestive heart failure.

Two-dimensional echocardiography (Logic 3, General Electric using a spectral $7 \mathrm{MHz}$ probe) demonstrated a dextropositioned aorta, a membranous ventricular septal defect, right ventricular hypertrophy and a stenotic pulmonary valve. Color and spectral Doppler echocardiography showed right-to-left shunting of blood through a large ventricular septal defect in the left ventricular outflow tract just below the aortic valve and a turbulent pulmonary flow compatible with pulmonic valvular stenosis. Pressure gradients in the pulmonary flow and the septal defect were not evaluated, because continuous-wave Doppler was not available.

After the diagnosis, given the poor prognosis, the animal's owner opted for euthanasia, and with his permission, necropsy was performed. Necropsy showed that the aortic basis was shifted to the right, which was also dilated and thin walled; a septal defect of $0.8 \mathrm{~cm}$ diameter just below the aortic semilunar valve (Fig. 1A); stenosis of the pulmonary semilunar valve showing a subvalvular fibrous ring and a dilated pulmonary trunk (Fig. 1B). There was also thickening of the right ventricle wall with hypertrophy of the papillary muscles and eccentric hypertrophy of the left ventricle 

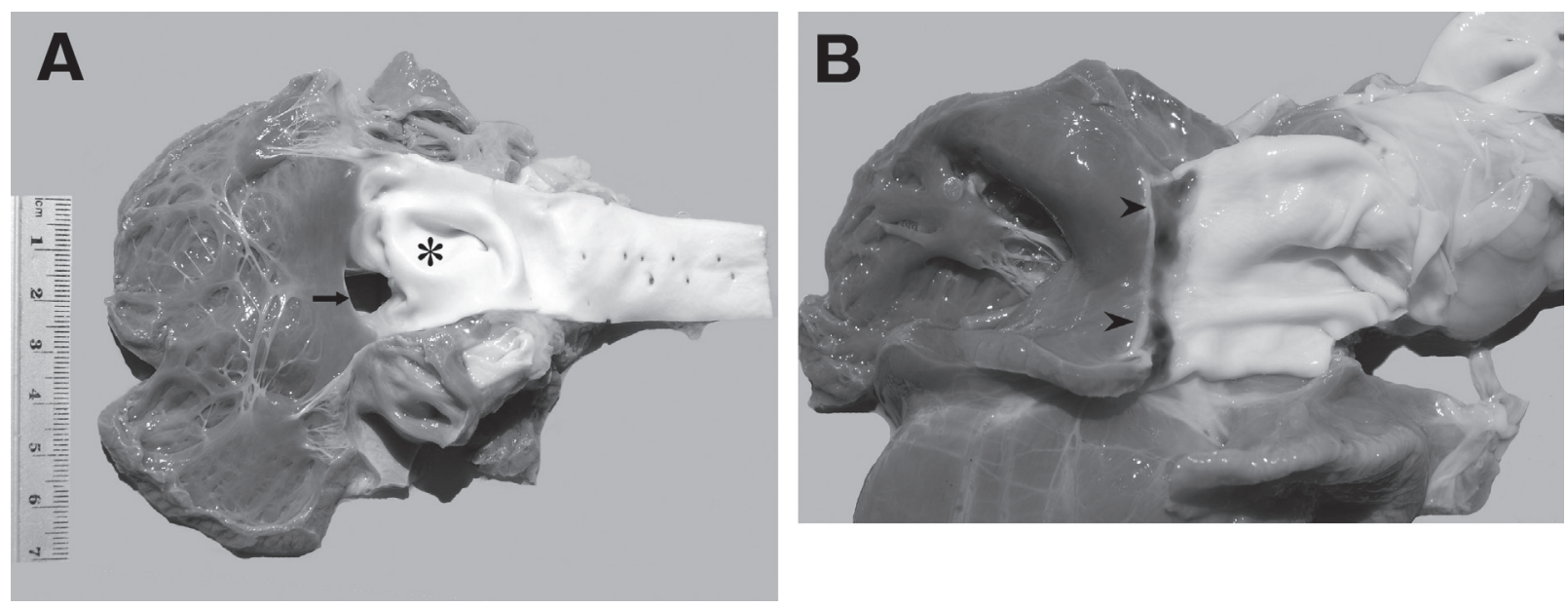

Fig. 1. Macroscopic examination of the heart: (A) a defect of the interventricular septum (arrow), widening of the base of the aorta (asterisk) and eccentric hypertrophy of the left ventricle; (B) a subvalvular fibrous annulus (arrow) with dilatation of the base of the pulmonary artery and right ventricular concentric hypertrophy (specially the papillary muscles).

Table 1. Values of cardiac troponin I in the animal with tetralogy of Fallot and 10 control animals of the same age and breed (mean and standard deviation)

\begin{tabular}{lc}
\hline & Serum cardiac troponin $\mathrm{I}(\mathrm{ng} / \mathrm{m} l)$ \\
\hline Tetralogy of Fallot & 0.78 \\
Control $(\mathrm{n}=10)$ & $0.008 \pm 0.003$ \\
\hline
\end{tabular}

with broad and flattened papillary muscles. These findings confirmed the diagnosis of tetralogy of Fallot.

The serum cardiac troponin I (Opus Plus, Boehring Diagnostica) concentration was $0.78 \mathrm{ng} / \mathrm{ml}$. Blood samples of 10 healthy lambs of the same breed and age were collected for comparison with the values of the lamb with tetralogy of Fallot (Table 1). The serum concentration of troponin I in the lamb with tetralogy of Fallot was much higher compared with lambs of the same progeny and age. Few studies have evaluated the serum concentrations of cardiac troponins in sheep. In a study that induced myocardial ischemia in adult sheep, the serum concentration of troponin I began to increase one day after the induction of injury and returned to physiological levels in 14 days [8].

Additionally, few studies have assessed the levels of cardiac troponins in patients with congenital heart disease. A study reported that the serum cTnI levels in children with atrial and ventricular septal defects were significantly higher than those in healthy children [14]. The significant volume and pressure overload at the ventricles because of congenital left-to-right shunt may cause myocardial damage. In these congenital cases, myocardial ischemia may be induced by ventricular enlargement, wall hypertrophy, elevation of end-diastolic pressure, tachycardia and several humoral factors associated with heart failure, such as cytokines and catecholamines [5]. In this case of tetralogy of Fallot, the shunt was right-to-left; however, concentric hypertrophy of the myocardium of the right ventricle (pressure overload) was observed due to pulmonary stenosis and an eccentric hypertrophy of the left ventricle by volume overload caused by the ventricular septal defect. These changes, added with the hypoxia resulting from the mixture of venous and arterial blood, could induce myocardial damage and ischemia. There were no histological changes in the myocardium. The finding of biochemical changes in the absence of morphological changes was possibly associated with the fact that injuries exert their effects first at molecular or biochemical levels; there is a time period between the stress and the morphologic changes of cell injury or death. Typically, the biochemical alterations precede ultrastructural, light microscopic and grossly visible morphologic changes [6].

This is the first report of increases in cardiac troponin I in a lamb with tetralogy of Fallot. Further investigation is required to relate the degree of myocardial damage caused by congenital heart disease to the increase in the cardiac troponins and their relationship with prognosis.

\section{REFERENCES}

1. Bolton, G. R., Ettinger, S. J. and Liu, S. K. 1972. Tetralogy of Fallot in three cats. J. Am. Vet. Med. Assoc. 160: 1622-1631. [Medline]

2. Coudrey, L. 1998. The troponins. Arch. Intern. Med. 158: 1173-1180. [Medline] [CrossRef]

3. Dennis, S. M. and Leipold, H. W. 1968. Congenital cardiac defects in lambs. Am. J. Vet. Res. 29: 2337-2340. [Medline]

4. Freitas, R. R., Stopiglia, A. J., Irino, E. T. and Larsson, M. H. M. A. 2003. Tetralogia de Fallot em cão. Cienc. Rural. 33: 1179-1184. [CrossRef]

5. Kogaki, S. 2011. Highly sensitive cardiac troponin-I in congenital heart disease. Circ. J. 75: 2056-2057. [Medline] [CrossRef]

6. Kumar, V., Abbas, A. K., Fausto, N. and Aster, J. C. 2010. Cellular responses to stress and toxic insults: adaptation, injury, and death. pp. 3-42. In: Robbins and Cotran Pathologic Basis of Disease, 8th ed. (Kumar, V., Abbas, A.K., Fausto, N. and Aster, 
J.C. eds.), Saunders Elsevier, Philadelphia.

7. Lacasta, D., Ruíz, S., Ramos, J. J., Ferrer, L. M., Fernández, A. and Gómez, P. 2011. Tetralogy of Fallot in a three-month-old lamb: clinical, ultrasonographic and laboratory findings. Vet. Rec. 169: 73-74. [Medline] [CrossRef]

8. Leonardi, F., Passeri, B., Fusari, A., De Razza, P., Beghi, C., Lorusso, R., Corradi, A. and Botti, P. 2008. Cardiac Troponin I (cTnI) concentration in an ovine model of myocardial ischemia. Res. Vet. Sci. 85: 141-144. [Medline] [CrossRef]

9. McKenna, S. L. B., Barkema, H. W., McClure, J. T. and Rogers, L. A. 2003. Tetralogy of Fallot in a 2-year-old Holstein heifer. Can. Vet. J. 44: 312-313. [Medline]

10. Mir, S. A., Nazki, A. R. and Raina, R. 2000. Comparative electrocardiographic studies, and differing effects of pentazocine on ECG, heart and respiratory rates in young sheep and goats. Small Rumin. Res. 37: 13-17. [Medline] [CrossRef]

11. Poteet, B. A. 2008. Radiology of the heart. pp. 24-48. In: Manu- al of Canine and Feline Cardiology, 4th ed. (Tilley, L. P., Smith, Jr. F. W. K., Oyama, M. A. and Sleeper. M. M. eds.), Saunders Elsevier, St. Louis.

12. Prickett, M. E., Reeves, J. T. and Zent, W. W. 1973. Tetralogy of fallot in a thoroughbred foal. J. Am. Vet. Med. Assoc. 162: 552-555. [Medline]

13. Strickland, K. N. 2008. Congenital heart disease. pp. 215-239. In: Manual of Canine and Feline Cardiology, 4th ed. (Tilley, L. P., Smith, Jr. F. W. K., Oyama, M. A. and Sleeper, M. M. eds.), Saunders Elsevier, St. Louis.

14. Sugimoto, M., Ota, K., Kajihama, A., Nakau, K., Manabe, H. and Kajino, H. 2011. Volume overload and pressure overload due to left-to-right shunt-induced myocardial injury: evaluation using a highly sensitive cardiac troponin-I assay in children with congenital heart disease. Circ. J. 75: 2213-2219. [Medline] [CrossRef] 